Educational Research for Social Change (ERSC)

Volume 8 No. 1, April 2019

pp. 86-100

ersc.nmmu.ac.za

ISSN: 2221-4070

\title{
The Agentic Capacities of Mundane Objects for Educational Equity: Narratives of Material Entanglements in a Culturally Diverse Urban Classroom
}

Adrian D. Martin

New Jersey City University

Amartin6@nicu.edu

\section{Abstract}

Research on teachers' professional practices to facilitate equity and social justice has often focused on pedagogical approaches or dispositions aligned with this aim. Less attention has been given to how interactions with material contexts, tools, or resources can also contribute towards such a purpose. This article reports on a study that sought to investigate the ways material resources served as a vehicle to promote social change and educational equity in a culturally and linguistically diverse early childhood classroom. The study reports on objects from the classroom of Valentina, a mid-career Latina preschool teacher in an urban context. Data sources were multiple observations of Valentina's teaching, audio-recorded and transcribed interviews, lesson plans, and reflections on her practice. Employing a new materialist theoretical lens, analysis suggests that the micropolitics of classroom activity reflect inter/intra-actions with myriad tools (i.e., objects) with the agentic capacities to advance educational equity. Classroom objects were chiefly employed to promote student learning. Nonetheless, they were also repurposed, both by Valentina and by her students, in ways that highlighted the objects' agentic capacities. Recommendations for future research on objects are provided.

Keywords: urban education, new materialism, early childhood, objects, social justice

Copyright: (ㅇ 2019 Adrian D. Martin

This is an open access article distributed under the terms of the Creative Commons Attribution NonCommercial License, which permits unrestricted non-commercial use, distribution, and reproduction in any medium, provided the original author and source are credited.

Please reference as: Martin, A.D. (2019). The Agentic Capacities of Mundane Objects for Educational Equity: Narratives of Material Entanglements in a Culturally Diverse Urban Classroom. Educational Research for Social Change, 8(1), 86-100. http://dx.doi.org/10.17159/22214070/2018/v8i1a6 


\section{Introduction}

The work of teachers is often conceived of as primarily concerned with imparting the content area and disciplinary knowledge and skills that students are expected to master. Whether teaching children in an early childhood setting, or young adults at the secondary level, educators are tasked to promote student learning, most often as specified in curricula and national or state academic standards (DarlingHammond, 2017; Whitton, Barker, Humphries, Nosworthy, \& Sinclair, 2016). However, for teachers working with students from marginalised communities (e.g., culturally and linguistically diverse, LGBTQ, disabled, working class, or poverty level), teachers' professional practices assume additional, perhaps even, moral imperatives (Cochran-Smith et al., 2009). Solely conveying the curriculum is insufficient. Rather, the professional responsibilities and endeavours of such educators include attending to and advocating for the affirmative inclusion of these students in their classrooms, schooling systems, and in the greater society at large (Banks \& Banks, 2016; McLaren, 2016). Teacher educators and education scholars have explored such a perspective through research on the dispositions, pedagogical frameworks, teaching strategies, and funds of knowledge possessed and enacted by social justice and equity-oriented educators (Gay, 2018; Sleeter \& Carmona, 2017; Strom $\&$ Martin, 2017). This work has served as a scholarly template for the education community towards identifying means of advancing a teacher workforce critically conscious of the necessity to enable welcoming, inviting, and supportive schooling contexts for all students but, especially, those most marginalised in society.

Recognising the qualities of an equity-oriented teacher who can engage in pedagogies conducive to affirming all students and supporting social justice is certainly integral to promoting inclusive classrooms. Often, this lens foregrounds the teacher herself, her professional identity, and enacted instructional practices attentive to the socio-emotional, sociopolitical, academic, and linguistic needs not only of students who represent the majority population, but students from diverse and historically marginalised communities as well (Lawrence-Brown \& Sapon-Shevin, 2014; Ovens, 2017). Yet teachers' work and interactions with students do not occur within a vacuum. The flow of classroom activity emerges through a complex interplay between and among various elements such as social norms and practices, discourses, rules, regulations, and policy initiatives (Martin \& Kamberelis, 2013; Strom, 2015). A salient element that mitigates processes of teaching and learning is the material context itself, and permutations of materiality such as objects found in classrooms and schools (Lather \& St. Pierre, 2013; Mills, 2017).

Nevertheless, much education research continues to position teachers and students as central agentic actors in analyses of classroom activity (Martin, 2018). While this body of work has advanced insight on teaching and learning, it has frequently failed to attend to the myriad ways that the materiality of the classroom itself, and the confluence of activity among and between the material, teachers, and students, coalesce as enabling (or inhibiting) the intended pedagogical results of instruction or opportunities for educational equity and social justice (Hickey-Moody, Palmer, \& Sayers, 2016; Taylor \& Ivinson, 2013). For education researchers to ignore the role of the material and materials' agentic capacities is to undermine a crucial and generative fount of insight with the potential to contribute to the aim of equity and justice in schools. An entry point for such work is the examination of objects themselves (i.e., the nonhuman actors in the multiplicity of elements found in classrooms) and the affective capacities they possess.

Historically, objects and their functions have been the subject of academic explorations. In the 19th century, German pedagogue Friedrich Fröbel conceptualised play materials as "gifts" to promote an appreciation for diverse forms of life, beauty, and knowledge (Wiebe, 2015). In the 20th century, paediatrician and psychoanalyst Donald Winnicott's (1953) concept of transitional objects sought to explain stages of dependence-independence in infants and children. Yet, in the present, research on 
objects in the field of education is an emergent domain of scholarly inquiry. Drawing from the work of Claudia Mitchell (2011) and social scientists in fields such as sociology and anthropology, education scholars (e.g., Pillay, Pithouse-Morgan, \& Naicker, 2017) have begun to take up Mitchell's thesis "that our relationships to things and objects are typically not simple and straightforward" and "the analysis of material objects offers the possibility of theorising abstract concepts in a grounded manner and, in so doing, expands the possibilities of what counts as evidence in research" (2017, p. 14). Empirical inquiry on objects (i.e., the material) is not solely a matter of discerning meaning or evaluating the efficacy of something but, rather, is a window of opportunity to generate "new and different knowledges and ways of knowing in educational research" (Pillay et al., 2017, p. 2).

For education researchers concerned with issues of equity and social justice, analyses of the conditions of schooling limited to the teacher-student relationship, or social discourses on education without consideration of the materiality of the educative context and the inter/intra-play of education stakeholders (i.e., the human) with the material (i.e., objects), is a narrow and anthropocentric caricature. By attending to material objects that are employed in schooling and in the pedagogical encounter, education scholars can construct a nuanced and textured portrait of classroom life and the myriad elements of experience that mitigate scholastic opportunities for educational equity and social justice.

The purpose of this study was to investigate forms of engagement with material resources in an urban early childhood classroom setting as contributing to educational equity for culturally and linguistically diverse students. The study, part of a larger study on the professional identities of teachers of English learners (Martin, 2016) attends to the experiences of Valentina (pseudonym), a mid-career Latina urban preschool teacher in the Northeastern United States. In this paper, I report on observations of Valentina's classroom and her work with her preschool students. Analysis suggests that the micropolitics of classroom activity reflect inter/intra-actions with myriad tools (i.e., objects) with agentic capacities to support educational equity. Classroom objects were chiefly employed to promote student learning. Nonetheless, they were also repurposed, both by Valentina and by her students, in ways that highlighted the multiplicitous capacities the objects possessed.

In the following section, I provide an overview of new materialism as the theoretical framework that guided this inquiry. Then, I discuss the research context and methodology. Findings are reported and subsequently discussed in relation to new materialism, object inquiry, and educational equity. Implications for future research are provided the conclusion.

\section{Theoretical Framework}

This study was informed by new materialism as a theoretical tool to consider the capacities of objects in education research, and the ways in which these enable or hinder opportunities for educational equity. New materialism refers to a collective body of conceptual and theoretical perspectives, many of which have emerged as a critique of humanistic principles or precepts in favour of emergent elucidations on ontology and epistemology-often referred to as post-humanism (Braidotti, 2013; Fox \& Alldred, 2014). Although theorists who employ a new materialist lens may diverge in their areas of focus, what they share is an emphasis on the materiality of the world, in effect, a "turn to matter" (Bennett, 2010; Fox \& Alldred, 2017). As such, this lens attends to the multiple, ongoing, and complex interactions within and amongst permutations of materiality (or assemblages), and how power circulates through these networks (Coole \& Frost, 2010). Therefore, new materialism focuses on how assemblages function, affect, and are affected (Deleuze \& Guattari, 1987). The human, animate, and inanimate in assemblages inter/intra-act via affect economies, or processes of affecting and being affected (Clough, 2004). Hence, the role of the human as prime actor in the conditions and circumstances of social activity is decentred. New materialism challenges assumptions relevant to 
binary divisions between the human-nonhuman, nature-culture, animate-inanimate, subject-object, and so forth (Braidotti, 2013). Instead, an ontology of monism is proposed, or a "flat ontology" wherein everything (human and nonhuman) that contributes to a phenomenon is explored and characterised via its relational activity (i.e., affect economies) without recourse to larger, conceptual structures (e.g., neoliberalism, heteronormativity). New materialism affords researchers an opportunity to consider the micro-politics between and among diverse elements (e.g., discourses, beliefs, actions, physical arrangements, emotions, objects) as material permutations that collectively contribute to social structures-rather than being the effects or results of such structures.

Drawing from the works of numerous theorists (e.g., Barad, 2007; Braidotti, 2013; Deleuze \& Guattari, 1987; Latour, 2007), Fox and Alldred (2017) identified numerous salient features of new materialism. First is the focus on matter itself, including how matter is produced, how it engages, and how it contributes to the world in its multiple, disparate manifestations (Coole \& Frost, 2010). From new materialism's monistic perspective, matter is "ontologically free. . . It is not 'opposed' to anything . . . nor is there anything inside or outside matter that makes it do what it does" (Fox \& Alldred, 2017, p. 23-24). Recourse on how matter engages with itself is a reflection of processes of engagement (the inter/intra-actions between and among the multiple elements that produce a phenomenon). For researchers, this suggests attending to what can be observed (what is imminently discernible), and grounding analyses in pragmatic considerations - in contrast to a search for transcendental truths or principles.

Second, new materialism emphasises what matter does, not what it is. Drawing from Deleuze and Guattari's (1987) concept of becoming - the ever changing and mutable characteristic of matter as a nonnormative ontology (Martin \& Kamberelis, 2013) - new materialism places a focus on the relations of matter and the ways in which these relations (or assemblages) are productive (Clough, 2004). The onus is exploring what matter does. To claim a definition of what matter is would rest upon an essentialised concept of it. This lens nullifies matter's capacity to become or to engage with other forms of matter in emergent ways that enable the production of something new. New materialism suggests researchers explore the relations and workings between and among forms of matter, the micro-politics of these inter/intra-actions, and how they produce the phenomena under investigation. Object-oriented researchers would attend to the relations between and among objects and the host of other elements in a given context (e.g., the classroom), and how these contribute towards the production of something such as pedagogical activity or opportunities for learning.

The third feature of new materialism is that the human, and human agency, are not privileged over the agency of other forms of matter. Agency is understood as the capacity to affect and to be affected (Martin, 2018). All matter has agentic capacities. The monistic ontology new materialism advances is one wherein the multiple permutations and combinations of matter are not at the sole effect of human action. Rather, as Fox and Alldred (2017) suggested, "all matter is emancipated from anthropocentric hierarchies" (p. 25). Objects and other nonhuman actors also possess agentic capacities (to affect and be affected) that emerge via the inter/intra-actions with other forms of matter.

Next, the fourth feature of new materialism is the perspective that memories, thoughts, desires, and emotions have material effects. Given new materialism's monistic ontology, the previously conceived cognitive constructs are levelled with the physical and the tangible as differentiations of matter and, as such, similarly possessing the ability to affect. This assemblage collapses the divide between the object-subject binary. Thoughts, feelings, memories, desires, and emotions are analysed as elements alongside tangible elements. This incorporates the fifth feature of new materialism: that these multiple assemblages reflect the capacities to affect, or be affected, within numerous associations and relations. Ontology is relational, ever shifting, and open to change. The meanings of objects and their 
workings surface in the complex composition of their use in physical spaces alongside the intangible (i.e., feelings, thoughts, and desires) that has a shaping effect on the objects' employment. Fox and Alldred (2017) asserted an additional feature, that social inquiry should be understood as a material and affective process. Thus, researchers must be attentive to, and conscious of, how their own engagement with the research endeavour and the multiple facets that inform a research study (or a research assemblage) contributes to the interpretation and understanding of study results. For inquiries on objects and material resources or tools, this and the other features function as conceptual windows through which to consider and analyse the workings of materiality (i.e., objects) as central analytic foci.

\section{Methodology}

This study was guided by the questions: "In what way are objects employed in an urban early childhood classroom?" and "How might such employment promote opportunities for educational equity and social justice?" The methods used in this study draw from a diverse body of methodological approaches in qualitative research, enabling a method with no methodology (Koro-Ljungberg, 2015). Elements of case study (Merriam, 2009), discourse analysis (Gee, 2014), narrative research (Riessman, 2008), and autoethnography (Adams, Jones, \& Ellis, 2015) contributed to the analytic protocols and the meaning making of the data. This confluence of methodological elements in conjunction with my role as researcher, Valentina as the teacher participant, and the host of variables that were part of her classroom informed the research assemblage (Fox \& Alldred, 2017) or aggregation of diverse factors that collectively shed light on the research questions. In this study, the lens of conceiving of the research activity as a research assemblage with new materialism as a guiding theoretical framework enabled me to consider the wide-ranging material resources made available in Valentina's classroom, the ways in which particular material resources (objects) were used, and the construction of narratives, to report the agentic capacities of these objects for educational equity and social justice.

\section{Context and Participant}

This study was conducted during a spring and summer semester in an urban early childhood classroom in the Northeastern United States. The school context was in Underhill (a pseudonym), a mid-sized city with a high percentage of residents at or below the poverty level, a majority from Central and South America, and many for whom English is a second language. Most of the students at the school in which the study was conducted received free or reduced lunch (a proxy for poverty-level status in the United States), are Hispanic or African-American, are the children of immigrants to the United States, or are immigrants themselves. This school had 10 early childhood (preschool) classrooms, each with a teacher and a paraprofessional (teacher's aide). All of the teachers in the school were English-Spanish bilingual and had varying years of professional experience. I gained access to the school site through an initial meeting with the school director. I contacted her in reference to the study, provided institutional review approval documentation, and was granted permission to conduct research at the school. I then contacted the teachers at the school about the opportunity to participate in the inquiry. Valentina was one of the educators who volunteered. Consent forms were provided and protocols for ethical research were abided by in alignment with the institutional review board policies.

At the time of the study, Valentina had been teaching exclusively for 10 years at the school in Underhill. Valentina self-identified as Hispanic, American, and as an English-Spanish bilingual. Having been raised in a neighbouring vicinity, Valentina possessed a personal history similar to many of her students. Like many of them, she was a first-generation American, the daughter of immigrants from the Caribbean and, during her schooling years, had attended schools similar to those in Underhill. Throughout her interviews, Valentina emphasised pride in her work as an educator, believing that her work extended beyond teaching elementary literacy and mathematical skills towards preparing her students for life in U.S. society and providing an early learning foundation so they would be able to positively contribute 
to the community as active, productive citizens. There were 15 students in her classroom, ranging in age from three to five years. Valentina was pursuing graduate coursework in urban education with a focus on teaching culturally and linguistically diverse students in urban contexts.

Valentina was aware that I was conducting this inquiry as part of larger study at the university I was affiliated with. I was a researcher-observer in her classroom and, like her, possessed years of professional practice as an urban early childhood educator. Furthermore, I also self-identify as Latino, am an English-Spanish bilingual, and possess a family history similar to Valentina's. Certainly, my positionality informed my meaning making of what I observed in Valentina's classroom (Martin, 2018). I provide this statement in an effort to be transparent and to support the trustworthiness of the inquiry.

\section{Data Collection}

The primary data source for this study was field notes of five observations conducted in Valentina's classroom. The observations were conducted throughout the school day and ranged between 45 minutes to one hour in length. Observations included Valentina working with her class as a whole, small group activities, and independent interactions with students during work time - a block of time during which students navigate throughout the classroom and work in a variety of learning centres. Field notes of these observations focused on documenting the scope of activities that Valentina and her students engaged in. The field notes were revisited to gain insight on the role of objects and material resources as salient elements in the classroom activities.

Secondary data sources were transcripts from five audio-recorded interviews with Valentina, a written reflection by her on a lesson she taught, and a researcher journal wherein I documented the unfolding of the research and my emergent meaning making of the data as I conducted the study. The interviews provided an opportunity for Valentina to comment on her understanding of herself as an educator, of her role as a teacher of young children, of culturally and linguistically diverse youth, and how personal and professional experiences contributed to her perspectives. After the conclusion of the study, I contacted Valentina to converse about the meaning making of the data relevant to objects, and to gain additional insight or clarification from her about the material resources in her classroom.

\section{Data Analysis}

Given the new materialist perspective employed for this study, I engaged in multiple rounds of reading the data sources to discern how the theoretical features identified by Fox and Alldred (2017) were reflected in the context of Valentina's classroom. Beginning with the field notes of the classroom observations, I reviewed these in relation to the materiality of the teaching and learning context, attending to how the material (and objects, more specifically) was an instrumental and salient feature of the environment. Thus, this work attends to specific objects in the classroom environment rather than to Valentina or the students themselves. Analysis of the observation field notes involved identifying the ways objects were employed, and attending to how objects enabled (or hindered) the flow of activities in the classroom. Thus, analysis took up the notion of distributed agency (Sullivan, 2016) - considering how objects partook in diverse affect economies.

Once I had identified how particular objects were contributing to classroom activity, I began analysis of the observed teaching and learning scenarios in relation to Valentina's interview transcripts and her written reflection on the observed lessons. I maintained analytic memos to keep record of my meaning making of the data, her comments on the observed sequences, and whether or not she discussed any of the salient objects. Subsequent to this, I returned to the observation field notes and analysed them in relation to the added insight generated from the other data sources. I collectively reviewed my notes 
and the analytic propositions I identified relative to objects in the classroom, and put philosophy to work (Strom \& Martin, 2013) by applying the features of new materialism to them. I then engaged in a member check process (Merriam, 2009) by following up with Valentina. I conferenced with her about my meaning making of the objects in her classroom and inquired for any additional information or insights she possessed about the objects under discussion. Valentina's additional commentary informed the analysis and was integral to the crafting of the object findings provided in the next section.

I now turn to the findings that emerged from analysis of the data sources, which are presented in the form of narratives. These moments of material entanglements between and among the classroom objects, Valentina, and her students provide a portrait snapshot that sheds light on the ways objects were employed in an urban early childhood classroom and how this employment promoted opportunities for educational equity and social justice. In each of these stories, classroom objects (mundane, everyday material elements of the classroom context) were chiefly employed to promote student learning. Nonetheless, they were also repurposed, both by Valentina and by her students, in ways that highlight the agentic capacities these objects possessed.

\section{Findings: Stones, Shaving Cream, and Tennis Balls}

Valentina's students were mostly from Central and South America, although one student was from the Middle East and a few others from Caribbean nations. As recent immigrants or children of immigrants, these young learners were immersed not only in a new schooling context (the first for most), but also a new community and social context. Throughout the study, Valentina expressed awareness that her students were involved in a multiplicity of learning experiences that extended beyond the formal curriculum and the emergent literacy and mathematics content and skills they were expected to master. As culturally and linguistically diverse individuals in the United States, these students were engaged in the dual processes of learning their heritage languages and cultures in addition to the dominant mainstream U.S. culture as well. Valentina expressed the belief that part of her work as a teacher was to support and validate her students' heritage languages and cultures, but to also support their engagement and understanding of the larger national culture as well. For her, providing the foundation for these students to become linguistically proficient (i.e., speakers of English) and culturally literate was vital towards the long-term goal of being able to access social and economic opportunities in U.S. society.

For the students, however, engagement in the classroom largely reflected a focus on the present and on their engagement with Valentina, with each other, and with the material resources in the classroom. Part of their daily routine involved a full hour in the morning and in the afternoon where students played or worked in a variety of learning centres. Among these were a house play area, a building area, a science centre, an art area, a sand-and-water table area, and a computer or technology area. Each of these areas was replete with a variety of tools, instruments, materials, and objects intended for student use. Members of the classroom (the students and Valentina) engaged and interacted with each other and with these material resources in multiple ways-entanglements that diverged from what could be considered normative employment of these tools. The narratives discussed in this section reflect incidents that transpired primarily during these one-hour periods, and reflect the agentic capacities of these objects. Three narratives are discussed, which demonstrate that mundane classrooms objects can function as enabling material elements that can contribute to opportunities for educational equity and social justice. Valentina's interview excerpts are included at the beginning of each section to illustrate her meaning making. 


\section{From River Stones to Cookies}

I had planned for them [the students] to use the stones in the science centre. That was my intention. But yeah, they started using the stones in the house play area. I didn't expect that. I didn't think about using them in the house play till I saw the children doing it. (Valentina, Interview \#3)

In the corner of the science centre, surrounded by magnifying glasses, microscopes, a poster of the butterfly's life cycle, and a small fish tank with Nemo (the class goldfish), was a small basket with a variety of stones. These stones had been gathered by Valentina and her students on a recent class trip. The park they had visited was near a river, and the variety of rocks and stones in the area had caught the interest of many of the students. In one interview, Valentina shared that both she and her students collected these rocks, which she subsequently brought to the classroom.

The stones made the journey from a wooded area to the urban classroom context. Valentina shared that the stones were of great interest to the students, and she encouraged them to use the magnifying glasses to observe the rocks' surfaces, to employ paper, pencils, crayons, and markers to depict their observations of the stones, and to use vivid words to describe the rocks. Pedagogically, Valentina indicated that these activities were aimed at prompting students' understanding of the natural world, of the ways scientists engage in observation, and in language development itself. Normatively, this was how the addition of the stones into the classroom environment was to be used.

During one particular observation, some of the students found a use for these rocks beyond their productivity for observation and scientific inquiry. Cristian (pseudonym) was a young immigrant boy from El Salvador, an emergent bilingual who was learning not only English, but his heritage language of Spanish as well. Cristian began rummaging through the basket and selected a number of stones, each smooth and flat. He brought these over to the house play area-a miniature replica of a kitchen with a refrigerator, oven, sink, and microwave. Cristian placed the stones into the sink and proceeded to pull a number of toy ingredients from the refrigerator: eggs, a carton of milk, a salt-and-pepper shaker, and bottle of syrup. He opened a cabinet drawer and pulled out a mixing bowl, spatula, and wooden spoon. The little boy then began to "pour" his ingredients into the bowl, stirring, mixing, and adding more of the selected ingredients. He pulled a baking tray from the oven and placed the stones into the mixing bowl with the other ingredients.

The wooden spoon swooshed the stones around. The little boy, quiet and working alone, continued to stir and mix his ingredients. Valentina, who was working with other students in the classroom, glanced over and saw Cristian working in the house play area. Two girls entered this area and began to work there as well. They asked Cristian (in Spanish) what he was doing, and he responded that he was cooking, making cookies in fact. He removed the stones from the bowl and placed them on the baking tray. Cristian placed the stones into the oven and then turned the dial on an egg-beater. After a few seconds, it rang and Cristian said the cookies were ready. One of the girls pulled the tray from the oven, and both she and Cristian began blowing on the "cookies" to cool them. The other girl exclaimed how wonderful the cookies smelled. She approached me (I was sitting nearby, taking notes) and inquired whether I thought they smelled good too. I said they did, and she smiled as she returned to the house play area.

As Valentina joined the group, she concurred that the cookies smelled great and asked Cristian and the girls what type of cookies these were, how they were made, and how might they be shared among the group. As the students responded, the cookies were passed about and greedily "consumed" as students took imaginary bites and patted their bellies. Other students approached to partake in the activity. At Valentina's suggestion, the children began to enact a bakery scenario, with some of the 
students as customers, and Cristian and the two girls as bakers. Spurred by Valentina's questions and comments, the children discussed the possible activities that a baker might conduct as part of her or his livelihood, what owning a bakery might be like, and what knowledge and skills (e.g., measurements, nutrition, literacy) would be needed to become a baker. Cristian announced that he would like to be a baker and continued to employ the tools and ingredients in the house play area with the stones to create other baked goods.

After the observation, Valentina shared that this was not the first time students had used the stones to create cookies. On another occasion, they had baked biscuits and even miniature pizza pies. Throughout these scenarios, the house play area had been reimagined (as a pizza parlour, a restaurant and, now, a bakery). These instances had surfaced from her students' interests and imaginations; while Valentina promoted insight of the more formal curriculum through these incidents (attending to language development and mathematical comprehension), employment of the stones as more than stones was a contributing factor that spurred the students' consideration of future possibilities. For Cristian, the agentic capacities of the stones lent themselves to repurposing and reimagining as cookies and, by extension, to an imagining of his future self as a baker, business owner, and skilled worker with the ability to contribute to his community. As a Latino immigrant from a poverty-level background, promoting his capacity towards expansive considerations for his future is vital-even at the early age of four. For this young boy, the smooth round flatness of the stones acted upon his imagination. In composition with the other material resources of the house play area, Valentina, and the other students, this assemblage contributed to a teaching-learning instance that functioned to advance opportunities for equity and social justice.

\section{From Shaving Cream to Letter Writing}

The shaving cream is messy. It's a mess! But it's good. It gets them [the students] to have an experience with the letters. Not just reading them or writing. Like, feeling. They like it, and I get more out of it than just using it when we're doing beauty salon. (Valentina, Interview \#3)

Thematic units were a central component of the curriculum in Valentina's classroom. Each month, a thematic focus was selected and literature, activities, and exercises connected to that theme were provided to the students. Valentina related that past units focused on dinosaurs, transportation, winter, and flowers and trees, which stemmed from the students' interests. At the time of the study, students were working through a unit on community helpers (mail carriers, fire-fighters, police officers, etc.). The dramatic play area had been transformed into a beauty salon and barbershop. Here, the children enacted the roles of hair stylists and beauticians as they transformed their "customers" (dolls and other action figures) with hair clips, combs, brushes, curlers, ribbons, and laces. Fashion magazines were stacked in a corner, and the children perused these as they selected a new look or makeover for their customers.

The magazines were from Valentina's home, and she had purchased many of the other materials at discount or thrift shops. Items of much popularity with the students were cans of shaving cream that Valentina had introduced into the classroom. Valentina related that she assisted students to dispense shaving cream onto a doll's or action figure's face so that whoever was playing the role of barber could provide the customer a shave. She shared that given the young age of her students, it was better to keep the shaving cream beyond their reach, and she regulated the amount used. During the observations, the shaving cream cans were visible on a high shelf, and I did not observe students requesting use of the shaving cream. 
Nonetheless, the shaving cream was used. On one occasion, during work time, a small group of students assembled at a kidney-shaped table. Before each child was a plastic plate, and Valentina dispensed a few dollops of shaving cream onto each plate before returning the can to its shelf. Valentina directed the children to use their pointer fingers to create swirls in the cream. She did so too, on her own plate. After about a minute, she proceeded to showcase flashcards-each printed with a different letter of the alphabet. First, she held up "c," and students were directed to create the letter in their shaving cream. Next was the letter "o," followed by "a." With each one, students were encouraged to say the name of the letter, make the letter's sound, and repeatedly trace the letter in their shaving cream with a finger. Valentina held one young girl's hand and moved it in the shaving cream. She repeated the cycle of letters a few times and, on the last rotation, held up the cards and asked the students to identify the letter displayed-rather than telling them which it was.

During the post-observation conference and follow up discussions, Valentina shared that while the initial intent of introducing the shaving cream into the classroom was in relation to the thematic unit, she also recognised that, for some students, tactile experiences are productive in supporting their learning, particularly in relation to literacy. For the students at that table, the use of shaving cream was not solely intended as a novel and engaging means of learning some letters. Instead, the shaving cream was repurposed as a tactile experiential tool to enable student learning -in this instance, mastery of those letters. The sensory experience enabled by the shaving cream was conducive to promoting these students' emergent literacy skills.

Agentic capacity was exerted by the shaving cream through its entanglement and engagement with students. The creamy whiteness, smooth texture, and malleability were inviting to the students. The cooling menthol sensation produced by contact with the shaving cream was enabling-a sensory production that prompted students to continue to trace and create letters with their fingers on the plates. For young learners, but most especially for these of culturally and linguistically diverse backgrounds, meaningful and productive learning experiences (especially in relation to language and literacy) are foundational to accessing social opportunities and benefits. Given the marginalisation of such students and others of low socioeconomic and poverty-level backgrounds, providing as many opportunities as possible (including opportunities beyond those normatively prescribed by curricula) to promote academic learning is a means of advancing educational equity and social justice. Although intended as a supplementary tool for the dramatic play area, the agentic capacities of the shaving cream contributed to more than an imaginary barbershop scenario; rather, they entangled with Valentina, her students, and the other elements of the classroom to foster letter and sound recognition. For those students, such an exercise was potentially significant in their literacy development-paper-and-pencil practice might not be enough, and the capacities of the shaving cream may have opened opportunities for learning that would otherwise have been missing.

\section{From Tennis Balls to Quiet Chairs}

I bought the tennis balls at a local discount store. I mean, when I started working with kids I knew it would be noisy. They're going to talk. They need to. They're kids. But to cut the noise I wanted to do something. Ms. Rodriguez in the other class told me about using tennis balls on the chairs. So far, it's helped. (Valentina, Interview \#4)

The above narratives provide examples of ways that objects in the classroom were repurposed during specific incidents with Valentina and her students. They highlight how objects were repurposed, and the affordances they enabled for the children in the class. However, the repurposing of some objects was not exclusive to a particular activity or lesson. Objects, such as tennis balls, could also be repurposed via routine functions. 
A noticeable feature of the classroom was that a number of chairs were modified with tennis balls. These were the seats that the children used and, thus, were small in comparison to regular sized chairs. The bottom of each leg was inserted into a tennis ball. According to Valentina, the students' chairs had been outfitted with a variety of neon yellow and green tennis balls to reduce the noise in the classroom (by eliminating the sounds of sliding chairs as the children transitioned about the space) and to reduce scratches on the floor. Tennis balls, designed for sports, were affecting both the auditory climate of the learning environment as well as the aesthetic quality of the classroom space. In discussion with Valentina after the study, she shared that the use of the tennis balls was a suggestion from a colleague (Ms. Rodriguez, a pseudonym). As with many of the classroom objects, Valentina had purchased the tennis balls, cut them, and placed them on the children's chairs. Students in the class at the time of the study had commenced the school year with this fixture to their chairs and, to them, it was an inherent facet of their classroom.

Little to no thought was given to the modification of the classroom chairs during the inquiry. Students shuffled about the room, pulling and pushing seats that easily slipped across the linoleum floor. The tennis balls were in and of themselves no longer a sporting tool or recreational device, but part of the assemblage that constituted the students' chairs. The routine and continuous repurposing of the tennis balls extended beyond their designed purpose and, instead, applied the objects' agentic qualities as conducive to auditory and aesthetic modifications. The loss of sounds of chairs scratching the floor contributed to a classroom context wherein noise was characterised as the hum of student work and teacher engagement with students, rather than a disruptive cacophony of metal legs scratching and scraping across linoleum tiles. These objects affected the tiles, allowing them to retain some of their integrity and lustre by prohibiting the metal legs they covered from coming into contact with them. Even without being proactively or consciously employed in a particular manner by students or Valentina towards a specific pedagogical, social, or developmental aim, these objects affected the teaching and learning scenarios as contextual mitigators.

\section{Discussion}

The findings of this study shed light on how objects, specifically everyday mundane objects, can be repurposed and, in the context of Valentina's classroom, contribute to a climate of educational equity. These objects (rocks, shaving cream, and tennis balls) functioned in ways that extended beyond their intended purpose. In the assemblage that is the classroom environment, the objects were entangled with myriad elements (e.g., Valentina, the students, their perspectives, life experiences, other objects, the surrounding community) in ways that facilitated teaching and learning opportunities. By foregrounding the materiality of the classroom context and honing in on object entanglements, the agentic capacities of these objects are highlighted, providing insight that would otherwise be lacking in an inquiry solely focused on Valentina and her students.

The new materialism perspective adopted in this study's analysis articulates how matter (in this work, objects) engaged and contributed to the environment and flow of activities in their contexts. Analysis of the observations and other data sources suggests how these objects cannot be defined as any singular thing; instead, emphasis is placed on what they do (Fox \& Alldred, 2017). Stones, shaving cream, and tennis balls are not confined to denotative parameters assigned to them. From the new materialism perspective, these objects are a multiplicity of capacities (Braidotti, 2013) - helping young children to envision potential future selves, enabling literacy development, and crafting the auditory and aesthetic climate of a classroom environment. For the children in this study who possess marginalised identities in the United States context, efforts towards equity and social justice not only in the educative experiences, but for their life experiences as well, is paramount for advancing a better quality of life for them and their communities (Gay, 2018; McLaren, 2016). This study suggests that it is not only the agentic actions of teachers (or other stakeholders) in the field of education that can 
contribute to this, but material objects as well. New materialism proposes that all matter has agency. The objects in this study possessed agency-the capacity to affect and be affected-via their entanglements with the other elements in the classroom. This examination of the micro-politics of classroom activity reflects the notion of flat ontology and how the sum of tangible (i.e., objects) and intangible (i.e., thoughts, feelings, emotions, desires) elements coalesce in affect economies (Clough, 2004) - the collectivity of the observed phenomena.

This flat ontology levels the privileging of one element (e.g., Valentina) over others (e.g., objects). Further, it builds the analysis of the objects' entanglements in the classroom from the observations and data sources themselves rather than larger social structures or frameworks (e.g., capitalism, neoliberalism) as a causal factor in analytic meaning making. For example, analysis with recourse to capitalism and neoliberalism might cite these as explanations for the use of tennis balls in Valentina's class. School funding is primarily generated within local municipalities in the United States. This system (rooted in capitalist, neoliberal, and meritocratic ideologies) disadvantages low socioeconomic and poverty-level communities. Schools, like those in Underhill, routinely face limited or reduced financial budgets. A normative analysis drawing on the mentioned ideologies may posit that the use of the tennis balls reflects these-a result of budget shortages and an inability to purchase appropriate furniture for the classroom. While this could be related to Valentina's decision to modify the chairs in her classroom (it was not, in fact), it diverts attention from what the tennis balls were affecting, and diminishes realisation of the capacity for matter (even mundane matter) to enact in unrealised and unexpected ways.

This inquiry demonstrates that objects in this early childhood classroom possessed agentic capacities that, via their repurposing, contributed to opportunities for educational equity. By adopting the new materialism framework, teacher and students were decentred as principal actors in the classroomand the materiality of the context itself was the subject of analysis. This highlights affordances for educators, researchers, and teacher educators to reconsider context and materiality as agentic and integral in the processes of teaching and learning and, ultimately, as mitigating factors beyond material's normative applications. It suggests a need to pay closer attention to the flow of activity in the classroom, particularly to seemingly mundane objects that can affect processes of teaching and learning. In this classroom, the identified objects were enabling and conducive elements in the students' educative experiences. However, the same might not be true in a different classroom setting. Similar objects may serve as limiting or inhibitive and thus, because of contextual differences, affect the classroom environment in divergent ways.

\section{Conclusion}

The exploration of objects in this study demonstrates the productiveness of object inquiry and this mode of research as a vehicle for educational and social change. The work highlights the agentic qualities of classroom objects and how engagement with them promoted capacities for equity not just within the classroom but, potentially, in the lives of students beyond their schooling years. Educators, and early childhood educators in particular, should be cognisant of the kinds of relationships they seek to construct with students as well as how materiality (and, more specifically, engagement with classroom objects) contributes to these relationships and to learning itself. Early childhood educators may possess an awareness of classroom objects or tools as instruments to facilitate learning, however, the value of schooling extends beyond academic mastery. Schooling, and the conditions of educational contexts (i.e., the materiality itself), can aid or hinder students' opportunities for learning in the present, and in later life opportunities as well. Recognising how the material can enable or contribute to educational equity may promote social change both within and beyond the walls of the classroom. 
A limitation of this work was the exclusive focus on objects in one setting at a specific point in time. Researchers interested in pursuing object-oriented inquiries of their own could consider exploring the same or similar objects in a variety of settings. How the objects entangle with a variety of elements in differing educational contexts may lead to greater insight on inter/intra-actions between and among teachers, students, and the material environment. Other researchers might focus on objects in one context over an extended period of time. This could clarify how longitudinal contextual changes affect objects' capacities to affect other elements of the classroom and school environments. Researchers could also investigate how narratives of classroom objects change or remain the same through multiple experiences of teachers and students. This inquiry provides narratives via my observations as the researcher and Valentina's commentary as research participant; other studies could directly engage teacher and student participants in their own meaning making of classroom objects. This would provide multiple articulations on the agentic capacities of objects among different members of the classroom community.

Ultimately, attending to objects in education research is a productive means to better understand phenomena in classrooms and schools. For researchers concerned with advancing equity and social justice, examining the materiality of schooling via object inquiry is as generative and integral as analyses of pedagogy and education policy. Education researchers are urged to expand beyond the normative parameters of their research foci, especially those primarily concerned with teachers or students as prime actors in academic settings. Adopting an object-oriented perspective can support new conceptualisations, interpretations, and insights on processes of teaching and learning. Interactions and engagement with classroom objects and other forms of materiality can serve not only mundane purposes, but can also be repurposed as tools to promote equitable educative experiences.

\section{References}

Adams, T. E., Jones, S. H., \& Ellis, C. (2015). Autoethnography. Oxford, UK: Oxford University Press.

Banks, J. A., \& Banks, C. A. (2016). Multicultural education: Issues and perspectives (9th ed.). Hoboken, USA: John Wiley \& Sons.

Barad, K. M. (2007). Meeting the universe halfway: Quantum physics and the entanglement of matter and meaning. Durham, USA: Duke University Press.

Bennett, J. (2010). Vibrant matter. Durham, USA: Duke University Press.

Braidotti, R. (2013). The posthuman. Cambridge, UK: Polity.

Clough, T. (2004). Future matters: Technoscience, global politics, and cultural criticism. Social Text, 22(3), 1-23.

Cochran-Smith, M., Shakman, K., Jong, C., Terrell, D., Barnatt, J., \& McQuillan, P. (2009). Good and just teaching: The case for social justice in teacher education. American Journal of Education, 115(3), 347-377. doi:10.1086/597493

Coole, D.H., \& Frost, S. (Eds.). (2010). New materialisms: Ontology, agency, and politics. Durham, USA: Duke University Press.

Darling-Hammond, L. (2017). Teacher education around the world: What can we learn from international practice? European Journal of Teacher Education, 40(3), 291-309. doi:10.1080/02619768.2017.1315399

Deleuze, G., \& Guattari, F. (1987). A thousand plateaus: Capitalism and schizophrenia. Minneapolis, USA: University of Minnesota Press. 
Fox, N. J., \& Alldred, P. (2014). New materialist social inquiry: Designs, methods and the researchassemblage. International Journal of Social Research Methodology, 18(4), 399-414. doi:10.1080/13645579.2014.921458

Fox, N. J., \& Alldred, P. (2017). Sociology and the new materialism: Theory, research, action. Los Angeles, USA: SAGE.

Gay, G. (2018). Culturally responsive teaching: Theory, research, and practice. New York, USA: Teachers College Press.

Gee, J. P. (2014). An introduction to discourse analysis: Theory and method. London, UK: Routledge.

Hickey-Moody, A., Palmer, H., \& Sayers, E. (2016). Diffractive pedagogies: Dancing across new materialist imaginaries. Gender and Education, 28(2), 213-229. doi:10.1080/09540253.2016.1140723

Koro-Ljungberg, M. (2015). Reconceptualizing qualitative research: Methodologies without methodologies. Thousand Oaks: USA: SAGE.

Lather, P., \& St. Pierre, E. (2013). Post-qualitative research. International Journal of Qualitative Studies in Education, 26(6), 629-633. doi:10.1080/09518398.2013.788752

Latour, B. (2007). Reassembling the social: An introduction to actor-network-theory. Oxford, UK: Oxford University Press.

Lawrence-Brown, D., \& Sapon-Shevin, M. (2014). Condition critical: Key principles for equitable and inclusive education. New York, USA: Teachers College Press.

Martin, A. D. (2016). The professional identities of mainstream teachers of English learners: $A$ discourse analysis (Unpublished doctoral dissertation). Montclair State University, USA.

Martin, A. D. (2018). Affective reverberations: The methodological excesses of a research assemblage. In K. Strom, T. Mills, \& A. Ovens (Eds.), Decentering the researcher in intimate scholarship: Critical posthuman methodological perspectives in education (pp. 9-23). Bingley, UK: Emerald. doi: 10.1108/S1479-368720180000031003

Martin, A. D., \& Kamberelis, G. (2013). Mapping not tracing: Qualitative educational research with political teeth. International Journal of Qualitative Studies in Education, 26(6), 668-679. doi:10.1080/09518398.2013.788756

McLaren, P. (2016). Pedagogy of insurrection: From resurrection to revolution. New York, USA: Peter Lang.

Merriam, S. B. (2009). Qualitative research: A guide to design and implementation. San Francisco, USA: Jossey-Bass.

Mills, T. (2017). Mangling expertise: Using post-coding analysis to complexify teacher learning. Issues in Teacher Education, 26(3), 128-144.

Mitchell, C. (2011). Doing visual research. London, UK: SAGE.

Mitchell, C. (2017). Object as subject. In D. Pillay, K. Pithouse-Morgan, \& I. Naicker (Eds.), Object medleys: Interpretive possibilities for educational research (pp. 11-28). Rotterdam, Netherlands: Sense.

Ovens, A. (2017). Putting complexity to work to think differently about transformative pedagogies in teacher education. Issues in Teacher Education, 26(3), 38-51.

Pillay, D., Pithouse-Morgan, K., \& Naicker, I. (2017). Object medleys: Interpretive possibilities for educational research. Rotterdam, Netherlands: Sense.

Riessman, C. K. (2008). Narrative methods for the human sciences. Los Angeles, USA: SAGE. 
Sleeter, C. E., \& Carmona, J. F. (2017). Un-standardizing curriculum: Multicultural teaching in the standards-based classroom. New York, USA: Teachers College Press.

Strom, K. J. (2015). Teaching as assemblage. Journal of Teacher Education, 66(4), 321-333. doi:10.1177/0022487115589990

Strom, K. J., \& Martin, A. D. (2013). Putting philosophy to work in the classroom: Using rhizomatics to deterritorialize neoliberal thought and practice. Studying Teacher Education: A Journal of Self-study of Teacher Education Practices, 9(3), 219-235. doi: 10.1080/17425964.2013.83097

Strom, K. J., \& Martin, A. D. (2017). Becoming-teacher: A rhizomatic look at first-year teaching. Rotterdam, Netherlands: Sense.

Sullivan, H. I. (2016). Agency in the Anthropocene: Goethe, radical reality, and the new materialisms. In J. A. McCarthy, S. M. Hilger, H. I. Sullivan, \& N. Saul (Eds.), The history of embodied cognition 1740-1920: The Lebenskraft-debate and radical reality in German science, music, and literature (pp. 285-304). doi: 10.1163/9789004309036_013

Taylor, C. A., \& Ivinson, G. (2013). Material feminisms: New directions for education. Gender and Education, 25(6), 665-670. doi:10.1080/09540253.2013.834617

Whitton, D., Barker, K., Humphries, J., Nosworthy, M., \& Sinclair, C. (Eds.). (2016). Learning for teaching: Teaching for learning. South Melbourne, Australia: Cengage Learning.

Wiebe, E. (2015). The paradise of childhood: A manual for self-instruction in Friedrich Fröbel's educational principles, and a practical guide to kindergartners. Springfield, USA: Leopold Classic Library.

Winnicott, D. W. (1953). Transitional objects and transitional phenomena: A study of the first not- me possession. International Journal of Psychoanalysis, 34, 89-97. 